\title{
РАЗВИТИЕ НЕФТЯНОЙ ПРОМЫШЛЕННОСТИ РОССИИ В ПЕРИОД МАКРОЭКОНОМИЧЕСКОЙ НЕСТАБИЛЬНОСТИ
}

\author{
(C) 2019 Конников Евгений Александрович \\ Институт промышленного менеджмента, экономики и торговли (ИПМЭиТ) \\ Санкт-Петербургский политехнический университет Петра Великого (СПбПУ), \\ Россия, Санкт-Петербург \\ E-mail: konnikov.evgeniy@gmail.com \\ (C) 2019 Конникова Ольга Анатольевна \\ Санкт-Петербургский государственный экономический университет (СПбГЭУ), \\ Россия, Санкт-Петербург, \\ E-mail: olga.a.konnikova@gmail.com \\ (c) 2019 Завричко Ольга Ивановна \\ Институт промышленного менеджмента, экономики и торговли (ИПМЭиТ) \\ Санкт-Петербургский политехнический университет Петра Великого (СПбПУ), \\ Россия, Санкт-Петербург \\ E-mail: olga.zavrichko@yandex.ru \\ (c) 2019 Забелин Борис Фёдорович \\ кандидат экономических наук, \\ Институт промышленного менеджмента, экономики и торговли (ИПМЭиТ) \\ Санкт-Петербургский политехнический университет Петра Великого (СПбПУ), \\ Россия, Санкт-Петербург \\ E-mail: zabelinbf@mail.ru
}

Актуальность вопроса, выбранного для исследования, напрямую связана со специализацией России в сфере международной торговли. В данной статье при помощи использования факторной модели проанализировано, как изменялся объем добычи нефти за 2005-2017 гг. и какие факторы повлияли на это, а также рассмотрено, как менялась данная динамика в период мирового кризиса (2008-2009 гг.) и в период введения санкций против России (2014 г.- наст вр.). На основе проведенного анализа оценены перспективы нефтепромышленности Российской Федерации.

Ключевые слова: нефтяная промышленность, российская экономика, макроэкономическая нестабильность, факторная модель

Россия обладает богатейшими запасами природных ресурсов, которые составляют основу хозяйства страны и определяют сырьевую направленность экономики. Добыча нефти ориентирована прежде всего на экспорт, в стране имеется достаточное количество ресурсов не только для обеспечения России, но и на продажу за ее пределы. Наличие обильных запасов природных ископаемых является финансовой основой для совершенствования экономики и увеличения производства внутри страны.

Особенность нефтяной промышленности заключается в том, что спрос является неэластичным, то есть при любой цене спрос будет оставаться постоянным. От объема запасов и грамотного использования природных ресурсов напрямую зависят темпы экономического роста страны, роль и вовлеченность в международное разделение труда, успешное развитие внешнеэкономических связей и социальная стабильность населения.

В первую очередь необходимо проанализировать изменение цен на нефть, поскольку оно прямым образом влияет на объем добычи в денежном выражении. Так сложилось, что все цены на нефть, даже в российских отчетах, ведутся в долларах. В данной работе мы рассмотрим периоды 2005-2015 гг. и 2005-2017 гг. в силу имеющихся данных в свободном доступе в официальных источниках [7].

На рисунке 1 представлен график с ценами за баррель нефти в текущих ценах на период с 


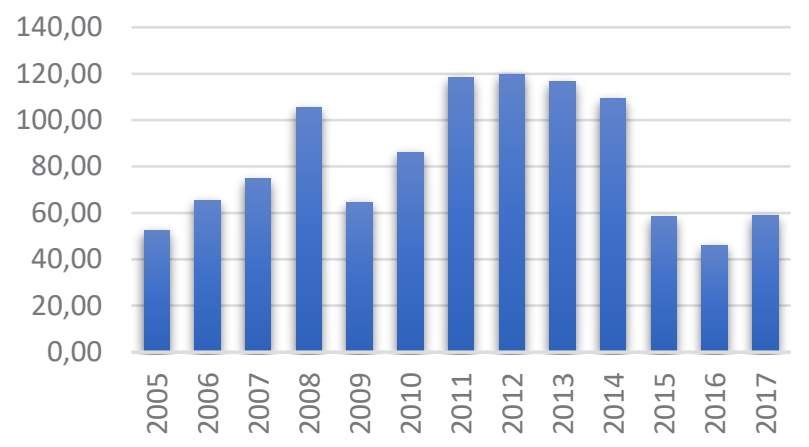

Рисунок 1. Текущие цены за баррель нефти в долл США в 2005-2017 гг.

\section{5 по 2017 гг.}

Согласно ТАСС, исторический максимум цены за баррель был зафиксирован 4 июля 2008 года $-\$ 143,95$, однако уже 26 декабря 2008 года произошел резкий обвал цен - \$33,73 вследствие мирового кризиса, начавшегося в США. Влияние оказалось достаточно сильным по следующим причинам:

- Процессы глобализации и взаимосвязь финансовых рынков различных государств делает их уязвимыми к негативным событиям, имеющим локальный характер. Вместе с падением курса акций на зарубежных рынках уменьшается и стоимость отечественных компаний, что отражается в их котировках на российском фондовом рынке;

- Спекулятивная игра с необоснованно высокими мировыми ценами на нефть, их обвал, обусловленный кризисной ситуацией, еще более углубил кризис фондовых рынков [2].

Однако нефтепромышленный рынок быстро восстановился. В 2011 году цена на нефть превысила $\$ 100$ за баррель из-за начала политического кризиса в Ливии и, тем самым, сокращения предложения ливийской нефти.

В 2014 году начинает наблюдаться падение цен из-за избыточного предложения, которое было вызвано высоким уровнем добычи нефти в США и возобновления поставок нефти из Ливии.
После ежемесячного доклада Международного энергетического агентства, прогнозирующего сокращение спроса на нефть, цена начала еще больше падать. Также важным фактором падения стоимости стала неготовность Организации стран-экспортеров нефти (ОПЕК) договориться о сокращении добычи. Таким образом, за год цены на нефть снизились на $51 \%$. Следом за этим, на падение цены повлиял кризис на фондовом рынке в Китае, планы Ирана по увеличению экспорта нефти после снятия санкций и данные о том, что в США продолжают вводить в строй новые добывающие мощности.

В ноябре 2016 года на встрече в Вене (Австрия) члены ОПЕК договорились с Россией и рядом других нефтедобывающих стран о сокращении добычи нефти. Всего страны - участницы соглашения договорились уменьшить добычу на 1,8 млн. баррелей по сравнению с уровнем октября 2016 года. Россия снизила среднесуточную добычу на 2,7\% (300 тыс. баррелей). Действие соглашения продлевалось до конца 2018 года, что поспособствовало сокращению предложения и росту цен на нефть [4].

Для корректности последующего анализа необходимо скорректировать текущие цены на индекс цен, чтобы получить сопоставимые цены для сравнения (см. рис. 2).

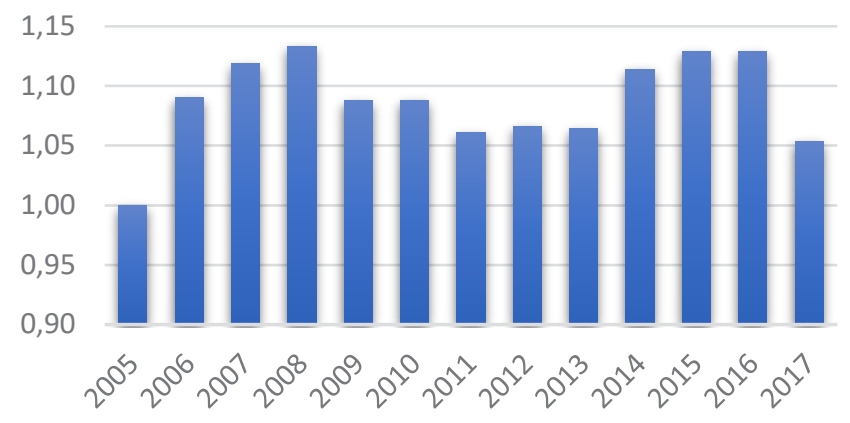

Рисунок 2. Индекс цен в 2005-2017 гг. 
Рассмотрим факторную модель ВП=ЧР*ГВ, где ВП - это выпуск продукции, ЧР - это численность рабочих и ГВ - среднегодовая выработка на одного рабочего.

В свободном доступе имеются данные о среднегодовой численности работников в нефтепромышленной деятельности только до 2015 года, поэтому будем рассматривать период 2005-2015 гг.

В таблице 1 представлены исходные данные для расчета факторной модели. Все данные взяты из сайта федеральной службы государственной статистики и Росстата. Прежде всего, применим индекс цен, чтобы сравнивать значения в сопоставимых ценах. Поскольку в международной практике применяется цена на нефть за баррель, переведем тонны нефти в баррели, что составляет примерно 159 литров. Среднегодо- вую выработку работника посчитаем как отношение выпуска продукции на численность рабочих.

В таблице 2 представлены итоговые данные, которые будут использованы при проведении факторного анализа.

Мы будем применять способ абсолютных разниц, чтобы понять, какой фактор и на сколько оказывал влияние на выпуск продукции.

$\Delta \mathrm{B} \Pi$ чр $=\Delta \mathrm{ЧP}^{*} \Gamma \mathrm{B} 0$

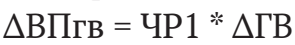

$\Delta \mathrm{B} \Pi=\Delta \mathrm{B}$ Пчр $+\Delta \mathrm{B}$ гв

Результаты проведенных расчетов представлены в таблице 3.

Для наибольшей наглядности продемонстрируем график, как менялись показатели с 2006 по 2015 гг. (рис. 3).

Таблиц̧а 1. Исходные данные

\begin{tabular}{|c|c|c|c|c|}
\hline Год & $\begin{array}{c}\text { Добыча нефти, } \\
\text { млн. тонн }\end{array}$ & $\begin{array}{c}\text { Тек цена } \\
\text { руб/млн. тонн }\end{array}$ & Индекс цен & ЧС, тыс чел \\
\hline 2005 & 470 & 330,45 & 1,0 & 136,1 \\
\hline 2006 & 481 & 411,77 & 1,09 & 134,1 \\
\hline 2007 & 470 & 469,85 & 1,12 & 134,2 \\
\hline 2008 & 478 & 662,88 & 1,13 & 111,6 \\
\hline 2009 & 495 & 406,44 & 1,09 & 108,9 \\
\hline 2010 & 505 & 541,68 & 1,09 & 106,6 \\
\hline 2011 & 512 & 743,61 & 1,06 & 108,7 \\
\hline 2012 & 519 & 753,87 & 1,07 & 113,4 \\
\hline 2013 & 522 & 734,02 & 1,06 & 122 \\
\hline 2014 & 527 & 688,57 & 1,11 & 1,13 \\
\hline 215 & 534 & 366,41 & & 18,9 \\
\hline
\end{tabular}

Таблица 2. Данные для факторного анализа

\begin{tabular}{|c|c|c|c|c|}
\hline Год & $\begin{array}{c}\text { Сопост. цены за бар- } \\
\text { рель, млн. долл }\end{array}$ & $\begin{array}{c}\text { ВП в сопоставимых } \\
\text { ценах, млн. долл }\end{array}$ & чр, тыс чел & гВ, млн. долл \\
\hline 2005 & 47,37 & 155310,34 & 136,1 & 1141,15 \\
\hline 2006 & 54,16 & 181706,31 & 134,1 & 1355,01 \\
\hline 2007 & 55,24 & 181098,76 & 134,2 & 1349,47 \\
\hline 2008 & 68,80 & 229388,58 & 120,5 & 1199,53 \\
\hline 2009 & 38,77 & 133867,87 & 111,6 & 1536,51 \\
\hline 2010 & 47,50 & 167325,93 & 108,9 & 2059,07 \\
\hline 2011 & 61,46 & 219496,65 & 106,6 & 1947,04 \\
\hline 2012 & 58,46 & 211642,83 & 108,7 & 1716,94 \\
\hline 2013 & 57 & 194701,02 & 113,4 & 1392,64 \\
\hline 2014 & 45,04 & 165585,27 & 118,9 & 648,16 \\
\hline 2015 & 21,23 & 79075,34 & 122 & \\
\hline
\end{tabular}


Таблица 3. Расчеты факторов методом абсолютных разниц

\begin{tabular}{|c|c|c|c|}
\hline Год & $\Delta$ ВПчр & $\Delta$ ВПгв & $\Delta$ ВП \\
\hline 2006 & $-2282,3$ & 28678,28 & 26395,98 \\
\hline 2007 & 135,5 & $-743,05$ & $-607,55$ \\
\hline 2008 & $-18487,7$ & 66777,54 & 48289,81 \\
\hline 2009 & $-16942,4$ & $-78578,3$ & $-95520,7$ \\
\hline 2010 & $-3238,74$ & 36696,8 & 33458,06 \\
\hline 2011 & $-3533,97$ & 55704,69 & 52170,71 \\
\hline 2012 & 4324,04 & $-12177,9$ & $-7853,82$ \\
\hline 2013 & 9151,07 & $-26092,9$ & $-16941,8$ \\
\hline 2014 & 9443,17 & $-38558,9$ & $-29115,8$ \\
\hline 2015 & 4317,2 & $-90827,1$ & $-86509,9$ \\
\hline
\end{tabular}

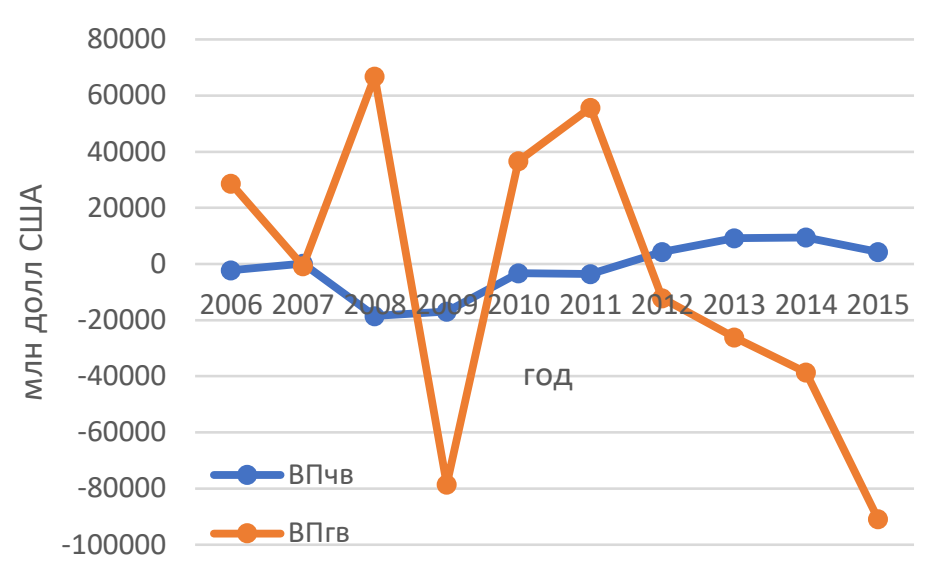

Рисунок 3. Динамика значений показателей для факторной модели

Анализ рис. 3 показывает, что наибольшее влияние на выпуск продукции оказывает среднегодовая выработка одним рабочим. Максимальное значение было в 2008 году за год до резкого падения, и составляло $+48289,81$ млн. долл, в т.ч. $+66777,54$ млн. долл благодаря изменению среднегодовой выработки и -18487,7 млн. долл за счет сокращения числа работников. Наименьшее значение (-95520,7 млн. долл) приходится на 2009 год, известный кризисом российского фондового рынка. На втором месте 2015 год $(-86509,9)$, включая наименьшее значение -90827,1 млн. долл среднегодовой выработки одного работника, поскольку в этом году наблюдалось резкое падение цен на нефть, что напрямую влияло на добычу нефти в денежном выражении. K тому же, в 2015 году стали наиболее ощутимы последствия санкций против России.

Так, согласно РБК, в сентябре 2014 года американские санкции ограничили доступ к аме- риканскому рынку капитала крупнейшим компаниям - «Газпром», «Роснефть», «Новатэк», «Транснефть» и «Газпром нефть». Российский нефтегазовый сектор на тот момент обеспечивал почти половину российского бюджета и около 70\% отечественного экспорта, что привело к значительному падению выручки. В 2015 году этот показатель стал меньше почти в 2 раза по сравнению с 2014 годом [6].

Далее проанализируем рентабельность продаж российской нефти в период с 2005 по 2017 гг.: как мировой финансовый кризис и санкции против России повлияли на выручку и прибыль, и как это отразилось на рентабельности продаж.

Рентабельность продаж рассчитывается как отношение прибыли на выручку. В данном случае будет под прибылью будем понимать экспорт нефти и нефтепродуктов. Важно отметить, что экспорт нефти и нефтепродуктов составляет 
порядка 47\%, что приносит значительный доход России. В стране находится около 5,5\% запасов мировой нефти. На 2015 год Россия занимала второе место по объемам экспорта нефти. Доход от экспорта топлива является одним из ключевых источников наполнения бюджета России и очевидным индикатором будущего состояния всей российской экономики [1].

В таблице 4 отражены данные экспорта за 2005-2017 гг. (источник: сайт gks.ru).

Приведем прибыль к сопоставимым ценам. Исходя из данных в таблице 4 также можно рассчитать сопоставимые цены за баррель нефти в 2005-2017 гг., что продемонстрировано на рисунке 4.

Продемонстрируем значения выручки и прибыли на графике (рис. 5).

Благодаря анализу рис. 5, видно, что выручка и экспорт имеют схожую тенденцию роста и падения в ценовом расчете. Как уже упоминалось, в 2009 году произошло резкое падение как добычи, так и экспорта нефти ввиду мирового кризиса. Примечательно, что до этого года и после шел рост производства в денежном выражении.

Показатель рентабельности показывает, что экспорт составляет около 50\% с тенденцией к уменьшению. Наименьшее значение наблюдается в 2014 году, когда были применены санкции по отношению к России, что привело к снижению экспорта. Стоит отметить, что после этого наблюдается небольшой ежегодный рост.

В связи с введением экономических санкций по отношению к России в связи с событиями на Украине, как и ожидалось, экспорт энергоресурсов из России начал снижаться после 2015 г., однако произошло переориентирование экспортной стратегии на азиатское направление. Так, например, в мае 2014 года был подписан контракт между «Газпромом» и Китайской национальной нефтегазовой корпорацией (CNPC) во

Таблица 4. Экспорт российской нефти в 2005-2017 гг.

\begin{tabular}{|c|c|c|}
\hline год & количество, млн. тонн & стоимость, млн. долларов \\
\hline 2005 & 252,50 & 83438,00 \\
\hline 2006 & 248,40 & 102282,90 \\
\hline 2007 & 258,60 & 121502,80 \\
\hline 2008 & 243,10 & 161147,00 \\
\hline 2009 & 247,50 & 100593,20 \\
\hline 2010 & 250,70 & 135799,30 \\
\hline 2011 & 244,50 & 181812,40 \\
\hline 2012 & 240,00 & 180929,70 \\
\hline 2013 & 236,60 & 173668,30 \\
\hline 2014 & 223,50 & 153895,50 \\
\hline 2015 & 244,50 & 89587,70 \\
\hline 2016 & 254,90 & 73712,60 \\
\hline 2017 & 252,80 & 93377,30 \\
\hline
\end{tabular}

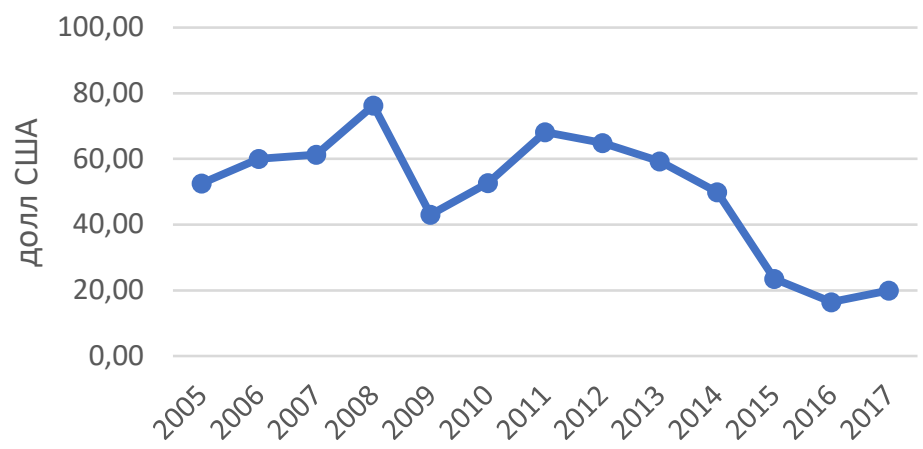

Рисунок 4. Сопоставимые цены за баррель российской нефти в 2005-2017 гг. 
Таблица 5. Расчет рентабельности экспорта нефти

\begin{tabular}{|c|c|c|c|}
\hline Год & $\begin{array}{c}\text { Выручка в соп ценах, } \\
\text { млн. долл }\end{array}$ & $\begin{array}{c}\text { Прибыль в соп ценах, } \\
\text { млн. долл }\end{array}$ & $\begin{array}{c}\text { Рентабельность } \\
\text { долл/долл }\end{array}$ \\
\hline 2005 & 155310,3 & 83438 & 0,54 \\
\hline 2006 & 181706,3 & 93837,52 & 0,52 \\
\hline 2007 & 181098,8 & 99642,85 & 0,55 \\
\hline 2008 & 229388,6 & 116661,85 & 0,51 \\
\hline 2009 & 133867,9 & 66933,93 & 0,50 \\
\hline 2010 & 167325,9 & 83066,56 & 0,50 \\
\hline 2011 & 219496,6 & 104818,22 & 0,48 \\
\hline 2012 & 211642,8 & 97869,62 & 0,46 \\
\hline 2013 & 194701 & 88249,54 & 0,45 \\
\hline 2014 & 165585,3 & 70224,49 & 0,42 \\
\hline 2015 & 79075,34 & 36205,84 & 0,46 \\
\hline 2016 & 56680,44 & 26383,94 & 0,47 \\
\hline 2017 & 68626,4 & 31716,19 & 0,46 \\
\hline
\end{tabular}

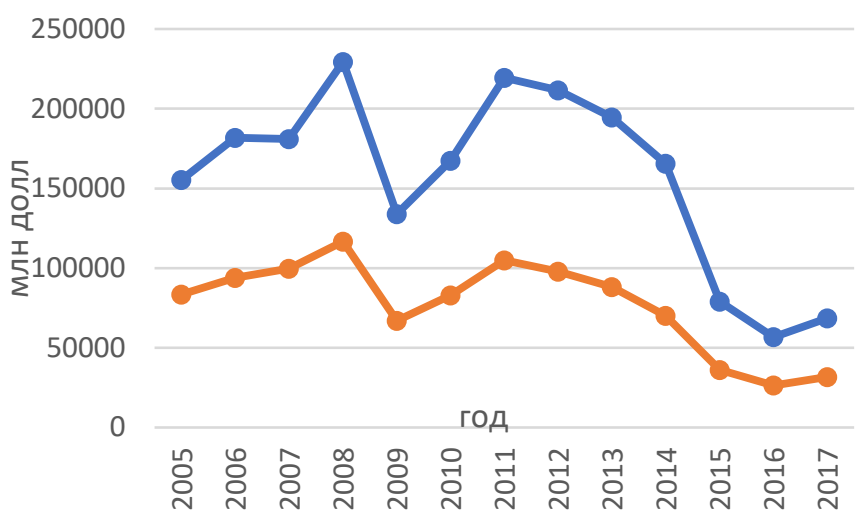

Рисунок 5. Выручка и прибыль от нефтепромышленности в сопоставимых ценах

время визита Владимира Путина в КНР. К тому же запасы нефти сокращаются, поэтому предполагается, что пик добычи нефти придется на 2015-2020 гг., а после рост объемов нефти и нефтепродуктов независимо от санкций, а также их доли в общем энергетическом экспорте России прекратится; одновременно начнут увеличиваться поставки газа, угля и электроники. Также прогнозируется, что экспорт нефти к 2040 г. снизится на треть [1].

Что касается стратегий по развитию, то Forbes отмечает, что санкции еще нанесут удар по российской нефтяной отрасли, поэтому необходимо начать инвестировать в новые технологии уже сейчас [8]. Если этого не предпринять, то с учетом зависимости экономики от нефтегазового сектора, это может привести к новому кризису.
Серьезная уязвимость российского нефтегазового сектора перед санкциями проявится к 2025 году, полагают эксперты Энергетического центра бизнес-школы «Сколково». Это следует из результатов исследования «Перспективы российской нефтедобычи: жизнь под санкциями». По мнению авторов доклада, отсутствие доступа к новому оборудованию и неразвитость собственных технологий нефтедобычи на фоне роста трудноизвлекаемых запасов начнет оказывать фатальное влияние на отрасль [3].

Невзирая на санкции США и ЕС, действующие уже более 4 лет, и низкую ценовую конъюнктуру, добыча нефти в России за пять лет (в период с 2012 по 2016 годы) выросла на 6\% - с 519 млн. т до 548 млн. т. Значительную роль в этом сыграли колоссальные инвестиции прошлых лет, существенные налоговые льготы и девальвация 
рубля. В этот период прирост добычи обеспечивался за счет ввода новых месторождений - добыча на них увеличилась на $77 \%$.

Татьяна Митрова, директор энергетической школы, отмечает, что обманчиво низкий эффект санкций стал для многих иллюзией, что они «не работают». Однако санкции действуют по принципу «сложного процента», с накапливающимся эффектом,- не для того, чтобы «наказать» или воздействовать немедленно. Начиная с 2020 года, негативные тенденции будут проявляться все более заметно и могут привести к снижению добычи нефти в России на 5\% к 2025 году и на 10\% к 2030 году от текущих уровней добычи. Снижение добычи в таких размерах, конечно, не катастрофично для российской экономики, но, тем не менее, достаточно чувствительно [3].

Нефтяные компании прикладывают усилия по созданию оборудования, работая над преодолением его дефицита для шельфовых проектов, гидроразрыва пласта и добычи сланцевой нефти. Тем не менее, программа по импортоза- мещению в нефтедобывающей отрасли показывает на данный момент неудовлетворительные результаты [5].

Таким образом, можно сделать вывод о том, что сокращение добычи нефти неизбежно, а санкции против России еще более усложняют ситуацию экспорта нефти из России. Ожидается, что к 2040 г. экспорт сырой нефти сократится на треть. Как результат, мы уже сейчас наблюдаем, как снижается и объем добычи, так и объем экспорта. Поспособствовать росту природных ресурсов невозможно, поэтому рекомендуется переориентироваться на другие виды промышленности и начать инвестировать новые технологии. Примечательно, что среди всех отраслей энергетики, только газовая и угольная отрасли обладают потенциалом наращивания присутствия на внешних рынках в ответ на изменение внешних условий [1], поэтому реинвестировать финансовые средства имеет смысл в развитие данных отраслей энергетики.

\section{Библиографический список}

1. Галкина А.А, Грушевенко Д.А., Грушевенко Е.В.. Перспективы развития мировой энергетики в период до 2040 г. и их влияние на российский топливно-энергетический комплекс // Научно-технические ведомости Санкт-Петербургского государственного политехнического университета. Санкт-Петербург., 2015 . № 1.

2. Егорова, Н.Е. Сценарии динамики индекса РТС в период послекризисного восстановления российского фондового рынка / Н.Е. Егорова, А.Р. Бахтизин, К.А. Торжевский // Экономика и математические методы / Российская академия наук. М., 2011. Т. 47, № 2. С. 54-58.

3. Конников Е.А., Конникова О.А., Шматко А.Д. Нечетко-множественный подход к анализу инвестиционного климата нефтегазовых рынков АТР. Международная конференция по мягким вычислениям и измерениям. 2018. T. 2. С. $422-425$.

4. Электронный ресурс: Динамика цен на нефть с 1990 года. Досье. URL: https://tass.ru/info/4903091 (дата обращения 23.05.2019)

5. Электронный ресурс: Нефть под санкциями: как Россия лишается будущего URL: https://www.forbes.ru/ biznes/358617-neft-pod-sankciyami-kak-rossiya-lishaetsya-budushchego. (дата обращения 24.05.2019)

6. Электронный ресурс: Санкции США ударили по 90\% российских нефтегазовых компаний. URL: https://www. rbc.ru/economics/12/09/2014/570422199a794760d3d41721 (дата обращения 24.05.2019)

7. Электронный ресурс: федеральная служба государственной статистики. URL: http://www.gks.ru/ (дата обращения 16.04.2019)

8. Аренков И.А., Домнин В.Н., Погребова О.А. Маркетинг и брендинг в нефтегазовой промышленности: учебное пособие под редакцией И.А. Аренкова. Санкт-Петербург, 2015. 198 с. 